\title{
CARACTERIZAÇÃO DE VARIEDADES DE BATATA DOCE (Ipomoea batatas L.) ATRAVÉS DE DESCRITORES MORFOLÓGICOS E ISOENZIMÁTICOS
}

\author{
MORPHOLOGICAL AND ISOENZYMATIC CHARACTERIZATION \\ OF SWEET POTATO (Ipomoea batatas L.)
}

\author{
Eliane Augustin $^{1}$ Alseny Garcia ${ }^{1}$ Beatriz Helena Gomes Rocha ${ }^{2}$
}

RESUMO

Ocorre grande variabilidade no germoplasma de batata-doce disponível no Rio Grande do Sul, mas nem todas populações podem ser caracterizadas através de aspectos morfológicos, havendo necessidade de recorrer a outros métodos, como análise de isoenzimas, para a sua diferenciação. A avaliação de características morfológicas e isoenzimáticas de dez acessos do Banco de Germoplasma de Hortaliças da Embrapa Clima Temperado foi o objetivo deste trabalho. Quatro descritores morfológicos foram utilizados, permitindo distinguir seis variedades. Análises de isoenzimas de peroxidase, aspartato transaminase e esterase foram efetuadas, utilizando-se eletroforese horizontal em gel de poliacrilamida. Foi observada similaridade máxima $(1,00)$ estimada através do coeficiente de Jaccard com base nesses marcadores, apenas entre as variedades Americana e Morada INTA. A análise de agrupamento permitiu a distinção de dois grupos e quatro subgrupos, utilizando UPGMA (método da média aritmética não ponderada). Os resultados obtidos permitiram a diferenciação dos dez acessos estudados $e$ indicaram que a análise de isoenzimas associada a avaliações morfológicas é de grande valia na caracterização de germoplasma de batata-doce disponível no Rio Grande do Sul.

Palavras-chave: peroxidase, aspartato transaminase, esterase.

\section{SUMMARY}

Despite the variability observed in sweet potato germplasm found in the Rio Grande do Sul State, many populations can not be morphologically characterized without the use of additional methods, such as isoenzyme analysis. The aim of this work was to evaluate the morphological and isoenzymatic characteristics of ten accesses of the genetic resources program of Embrapa Clima Temperado. Four morphological descriptors were used, which allowed to distinguish six varieties. Polyacrylamyde electrophoresis was used to analyze peroxidase, aspartate transaminase and esterase isoenzymes. Maximum similarity (1.00), estimated through Jaccard coefficient, was observed only in comparisons between Americana and Morada INTA. Varieties were classified into two groups and four subgroups, using UPGMA (unweighted pair-group method with arithmetic averages). All accesses could be differentiated. The results obtained indicated that isoenzyme analysis, associated to morphological evaluations, can be succesfully used to characterize sweet potato germplasm available in the Rio Grande do Sul.

Key words: peroxidase, aspartate transaminase, esterase.

\section{INTRODUÇÃO}

A cultura da batata-doce tem grande repercussão econômica na região sul do Brasil, onde encontra-se $61 \%$ da área plantada no país. O Rio Grande do Sul é o principal produtor nacional (39\%), com um rendimento médio de 10,95 t/ha (IBGE, 1995). O baixo rendimento se deve a vários fatores, entre os quais está incluída a má qualidade das variedades usadas. São utilizadas para plantio populações existentes nas áreas produtoras, do mesmo modo que nas demais regiões brasileiras.

O modo de propagação da espécie, aliado à ocorrência de fungos dos gêneros Phoma e Phomopsis, que vem causando sérios problemas à cultura (GARCIA et al., 1989), indicam a perda desses recursos genéticos. Por esse motivo, desde 1988 são conduzidas atividades de coleta, conservação, caracterização e uso desse germoplasma na EMBRAPA - Clima Temperado.

A caracterização e avaliação, além de proporcionar melhor conhecimento do germoplasma

\footnotetext{
${ }^{1}$ Engenheiro Agrônomo, Doutor, Embrapa Clima Temperado, CP 403, 96001-970, Pelotas, RS. Autor para correspondência.

${ }^{2}$ Engenheiro Agrônomo, Doutorando, Universidade Federal de Pelotas, CP 354, 96010-970, Pelotas, RS
}

Recebido para publicação em 01.06.98. Aprovado em 07.04.99 
disponível, permite a identificação dos acessos duplicados, o estabelecimento de coleções nucleares e a identificação dos modos de reprodução predominantes nos acessos. O processo passa por cinco etapas desde a correta identificação botânica até a avaliação complementar. Esse processo pode ser enriquecido por atividades de caracterização reprodutiva ou bioquímica, através de análises baseadas em eletroforese, cromatografia ou serologia. Sua utilização destina-se à identificação de duplicações, definição de parâmetros estritos para certos acessos ou prospecção da variabilidade intrínseca ou entre acessos de uma mesma espécie (VALLS, 1988).

A eletroforese de isoenzimas tem sido utilizada com sucesso, evidenciando possibilidades de grande eliminação de desperdício pela acurada identificação de duplicações antes da incorporação de acessos a etapas complementares do processo de avaliação (VALLS, 1988). Além dessa, outras técnicas eletroforéticas podem ser utilizadas para análise e caracterização de recursos genéticos vegetais. A análise de isoenzimas, no entanto, além do custo reduzido em comparação às demais, permite a análise de um número maior de amostras (AMAN, 1997).

No Brasil, há grande confusão e indefinição quanto aos nomes da maioria dos cultivares de propagação vegetativa, incluindo batata-doce (FILGUEIRA, 1981). Diferentes nomes são dados a uma mesma variedade, dependendo da localidade. Várias características contrastantes são citadas nas variedades em disponibilidade (FILGUEIRA, 1981; GARCIA et al., 1989). Algumas populações são facilmente caracterizadas por aspectos morfológicos, mas existem outras muito semelhantes, havendo necessidade de recorrer a diferentes métodos para sua diferenciação. $O$ objetivo deste trabalho foi caracterizar germoplasma de batata-doce disponível no Rio Grande do Sul através de marcadores morfológicos e isoenzimáticos.

\section{MATERIAL E MÉTODOS}

As variedades utilizadas, listadas na tabela 1, foram coletadas ou introduzidas e incorporadas ao Banco de Germoplasma de Hortaliças da Embrapa Clima Temperado. Os quatro descritores morfológicos utilizados para caracterização foram cor da folha, hábito, coloração da casca e polpa das raízes.

Para caracterização isoenzimática foi utilizada eletroforese horizontal em gel de poliacrilamida em concentrações de 8 e $7 \%$ para análises de peroxidase (PRX) e de aspartato transaminase (AT) e de $6 \%$, acrescido de $8 \%$ de sacarose, para análises de esterase (EST) em cascas de ramas situadas entre a quarta e a quinta folhas. Amostras de quatro plantas de cada variedade foram coletadas antes da floração de plantas mantidas em estufa plástica, na Embrapa Clima Temperado. A extração foi feita em placas de porcelana, com bastão de vidro, em solução 1:1 dos tampões lítio-borato e tris-citrato em $\mathrm{pH}$ 8,3, acrescida de $0,15 \%$ de 2 -mercaptoetanol (PRX), adicionando-se também $25 \%$ do peso da amostra (10 $\mathrm{mg}$ ) de polivinilpolipirrolidona (EST) ou $20 \%$ do peso da amostra de gelatina (AT).

Foi utilizado o sistema de tampões citado por SCANDALIOS (1969) no preparo dos géis e eletrodos. Para a revelação das isoenzimas de PRX e EST foi empregado o método descrito por SCANDALIOS (1969) e o de AYALA et al. (1974) para as de AT. A fixação foi efetuada com etanol:água, na proporção de 1:1 (PRX) e com metanol:água:ácido acético, na proporção de 5:5:1 (AT e EST).

As mobilidades relativas foram calculadas usando-se a linha de frente (PRX) ou uma banda comum a todas as amostras, tomada como padrão. As análises de similaridade genética e de agrupamento, baseadas nas variantes eletroforéticas encontradas, foram efetuadas através do NTSYS (Numerical Taxonomy and Multivariate Analysis for Personal Computers, v. 1.5), utilizando-se o coeficiente de Jaccard e UPGMA (unweighted pair-group method with arithmetic averages), conforme ROHLF (1989).

\section{RESULTADOS E DISCUSSÃO}

A avaliação de caracteres morfológicos da parte aérea das plantas (hábito e cor da folha) e das raízes (coloração da polpa e da casca) permitiram a diferenciação de seis variedades (tabela 1). Entretanto, não foi possível distinguir as variedades Americana, Diamante, Prata e Brazlândia Branca.

As variedades de polpa branca, como Americana, Da Costa, Diamante, Prata e Brazlândia Branca, são predominantes nas regiões de cultivo, o que se explica, além das preferências do mercado, pela alogamia e por ser a coloração branca incompletamente dominante sobre a amarela (HERNANDEZ et al., 1965). As variedades de polpa amarela, como Abóbora e Morada INTA, são mais ricas em pró-vitamina A (FILGUEIRA, 1981). O teor de caroteno é, provavelmente, controlado por seis genes, com ação aditiva (HERNANDEZ $\boldsymbol{e t}$ al., 1965). Variedades totalmente roxas, como a Roxa, não indicada para consumo in natura e ideal para fabricação de doce em calda, são mais dificilmente encontradas. Algumas dessas revelam altos teores de fibra, característica condicionada por dois grupos de genes; um controla a presença e o outro o tamanho da fibra (HAMMET et al., 1966). 
Tabela 1 - Procedência e caracteres morfológicos da parte aérea e das raízes das plantas de dez variedades de batata-doce. Pelotas, RS.

\begin{tabular}{llccc}
\hline \multicolumn{1}{c}{ Variedade } & \multicolumn{1}{c}{ Procedência } & Cor da Folha & Hábito & Cor da Casca \\
& & & & \\
& & & \\
Cristal & Pelotas, RS (coleta) & verde & rasteiro & branca \\
Americana & Barra do Ribeiro, RS (coleta) & verde & rasteiro & creme \\
Morada INTA & INTA, Argentina (introdução) & verde & semi-ereto & arroxeada \\
Abóbora & Pelotas, RS (coleta) & verde & rasteiro & arroxeada \\
Japonesa & São Lourenço do Sul, RS (coleta) & verde & rasteiro & roxa amarela \\
Da Costa & Barra do Ribeiro, RS (coleta) & arroxeada & rasteiro & branca \\
Diamante & Pelotas, RS (coleta) & verde & rasteiro & branca \\
Prata & Pelotas, RS (coleta) & verde & rasteiro & branca \\
Brazlândia Branca & branca \\
Roxa & CNPH, Brasília, DF (introdução) & verde & rasteiro & branca \\
& Pelotas, RS (coleta) & verde & rasteiro & roxa \\
& & & branca \\
\end{tabular}

As análises de peroxidase revelaram quatro padrões isoenzimáticos, com duas bandas polimórficas (figura 1). Nos sistemas isoenzimáticos de aspartato transaminase, foram observados três e no de esterase, sete padrões (figuras 2 e 3 ), com duas e todas as bandas polimórficas, respectivamente. Não foram encontradas variações intravarietais nas amostras analisadas.

Os coeficientes de similaridade genética (tabela 2) apresentaram o valor máximo de 1,00 entre as variedades Americana e Morada INTA, seguido de 0,93, entre Americana e Abóbora, e entre Morada INTA e Abóbora, e o mínimo de 0,53, nas comparações entre Cristal e Da Costa, Cristal e Diamante, Cristal e Prata, Abóbora e Brazlândia Branca e entre Diamante e Roxa.

O agrupamento dos acessos representado pelo dendograma apresentado na figura 4 permitiu distinguir dois grupos, sendo cada um deles consti-

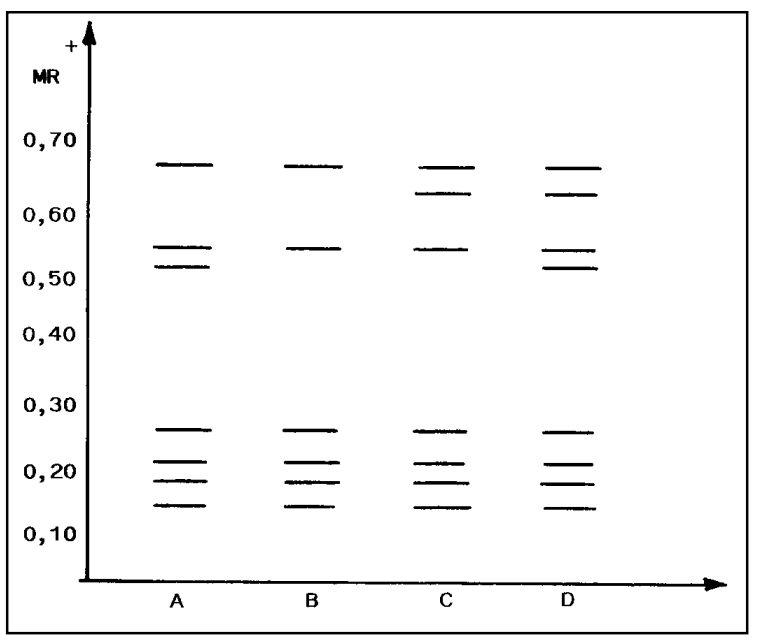

Figura 1 - Padrões isoenzimáticos de peroxidase. A-Cristal, Americana, Morada INTA e Abóbora; B-Japonesa ou Roxinha, Da Costa e Diamante; C-Prata e Brazlândia Branca; D-Roxa. tuído por dois subgrupos, compostos pelas seguintes variedades: I - Cristal, Japonesa ou Roxinha; II Americana, Morada INTA, Abóbora e Diamante; III - Da Costa e Prata; IV - Brazlândia Branca e Roxa.

Apenas Americana e Morada INTA não foram distinguidas através dos padrões isoenzimáticos observados. Avaliações de características morfológicas, no entanto, permitiram sua diferenciação (tabela 1). Por outro lado, Americana, Diamante, Prata e Brazlândia Branca apresentaram as mesmas características morfológicas, mas foram diferenciadas através da análise de isoenzimas.

Segundo Hamrick, citado por AMARAL Jr. et al. (1994), dependendo da espécie e variáveis utilizadas, podem ou não ocorrer associações entre caracteres isoenzimáticos e morfométricos. Esses autores utilizaram seis descritores botânicoagronômicos e observaram maior eficiência na dis-

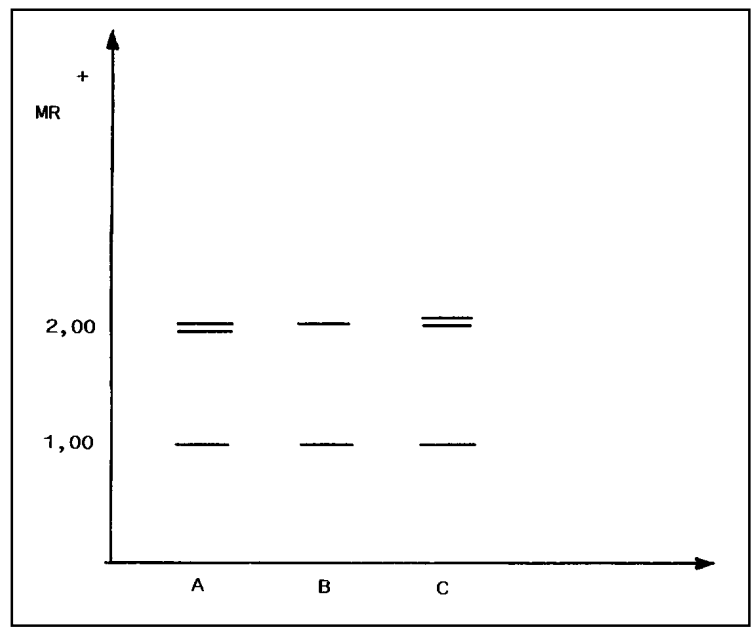

Figura 2 - Padrões isoenzimáticos de aspartato transaminase. ACristal, Japonesa ou Roxinha, Da Costa, Prata, Brazlândia Branca e Roxa; B-Americana e Morada INTA;C-Abóbora e Diamante.

Ciência Rural, v. 30, n. 1, 2000. 


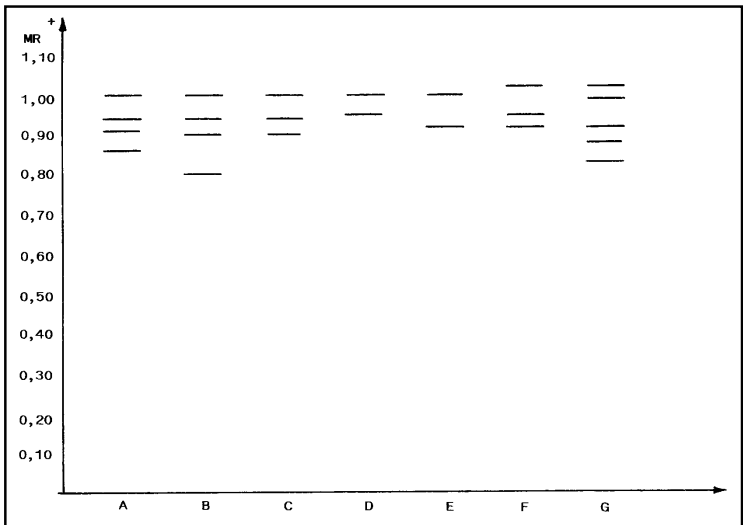

Figura 3 - Padrões isoenzimáticos de esterase. A-Americana, Abóbora, Diamante e Morada INTA; B-Da Costa; CPrata; D-Roxa; E-Brazlândia Branca; F-Cristal; GJaponesa ou Roxinha.

criminação genotípica de clones de couve-comum, em relação a sete caracteres isoenzimáticos analisados. Também foi citado que, tratando-se de espécie de propagação vegetativa, pode ter ocorrido estreitamento genético, como conseqüência da pressão seletiva aplicada pelos produtores ao longo do processo de domesticação. O mesmo poderia ter ocorrido com a batata-doce, que apresenta o mesmo modo de propagação. Nessa espécie, também, a caracterização isoenzimática, apesar do pequeno número de locos analisados, foi mais eficiente do que a morfológica, e a associação de ambas permitiu a diferenciação de todas as variedades estudadas.

A escolha dos sistemas enzimáticos foi baseada na maior nitidez e repetibilidade das bandas, após ajuste de metodologia no que se refere a tecidos analisados, concentração de géis e sistemas de tampões e de coloração. Para avaliação de um número maior de acessos, no entanto, possivelmente, seja necessária a análise de outros sistemas enzimáticos e a utilização de marcadores moleculares que permi-

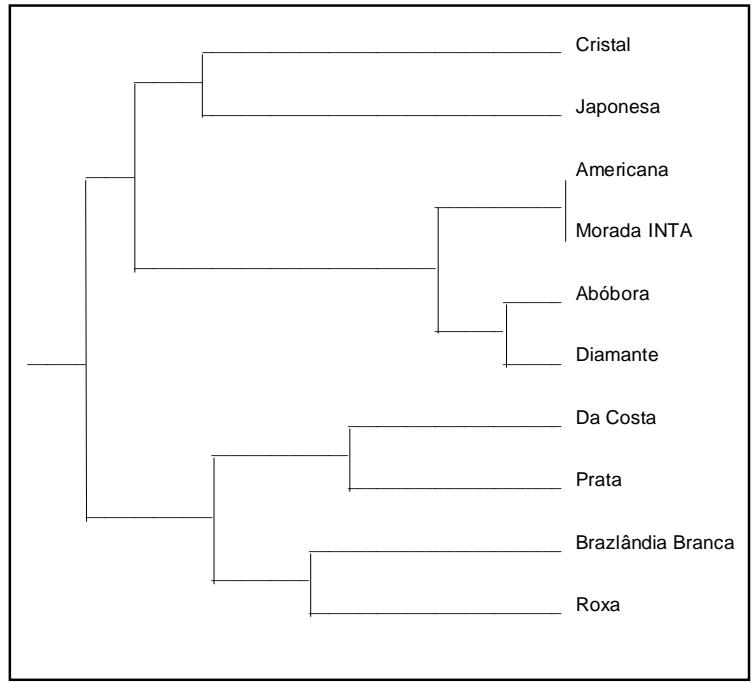

Figura 4 - Dendograma de dez variedades de batata-doce baseado na similaridade genética determinada pelo método UPGMA.

tem detectar polimorfismos em nível de DNA, os quais são amplamente usados para caracterização e avaliação da diversidade genética em espécies vegetais (KARP \& EDWARDS, 1997).

\section{CONCLUSÃO}

A análise de isoenzimas associada a avaliações morfológicas é de grande valia na caracterização de germoplasma de batata-doce disponível no Rio Grande do Sul.

\section{AGRADECIMENTOS}

Os autores agradecem ao CNPQ pela concessão de bolsas, à assistente de operações Ema Gladis Schultz Corrêa pela execução das análises eletroforéticas e ao técnico agrícola Pedro Files pela condução das atividades desenvolvidas em campos experimentais.

Tabela 2 - Estimativas de similaridade genética entre dez variedades de batata-doce baseadas em padrões isoenzimáticos.

\begin{tabular}{|c|c|c|c|c|c|c|c|c|c|}
\hline & Cristal & Americana & Morada INTA & Abóbora & Japonesa & Da Costa & Diamante & Prata & $\begin{array}{c}\text { Brazl. } \\
\text { Branca }\end{array}$ \\
\hline Americana & 0,63 & & & & & & & & \\
\hline Morada INTA & 0,63 & 1,00 & & & & & & & \\
\hline Abóbora & 0,59 & 0,93 & 0,93 & & & & & & \\
\hline Japonesa & 0,69 & 0,69 & 0,69 & 0,65 & & & & & \\
\hline Da Costa & 0,53 & 0,63 & 0,63 & 0,59 & 0,59 & & & & \\
\hline Diamante & 0,53 & 0,86 & 0,86 & 0,93 & 0,60 & 0,63 & & & \\
\hline Prata & 0,53 & 0,63 & 0,63 & 0,59 & 0,59 & 0,86 & 0,63 & & \\
\hline Brazl. Branca & 0,56 & 0,56 & 0,56 & 0,53 & 0,63 & 0,67 & 0,56 & 0,79 & \\
\hline Roxa & 0,73 & 0,63 & 0,63 & 0,59 & 0,59 & 0,63 & 0,53 & 0,73 & 0,79 \\
\hline
\end{tabular}

Ciência Rural, v. 30, n. 1, 2000. 


\section{REFERÊNCIAS BIBLIOGRÁFICAS}

AMAN, R.A. A comparative assessment of molecular techniques employed in genetic diversity studies (and their suitability in resource-limited settings). In: AYAD, W.G., HODGKIN, T., JARADAT, T.A. et al. Molecular genetic techniques for plant genetic resources. Rome: IPGRI, 1997, p. 119-127.

AMARAL JR., A.T. do, SILVA, D.J. H. da, SEDIYAMA, M.A.N. et al. Dissimilaridade genética de descritores botânico-agronômicos e isoenzimáticos em clones de couvecomum. Horticultura Brasileira, Brasília, v. 12, n. 2, p. $113-$ 117, 1994.

AYALA, F.J., TRACEY, M.T., BARR, L.G. et al. Genetic variation in natural populations of Drosophila species and the hypothesis of the selective neutrality of protein polymorphisms. Genetics, Maryland, v. 77, p. 343-384, 1974.

FILGUEIRA, F.A.R. Manual de olericultura: cultura e comercialização de hortaliças. São Paulo: Ceres, 1981, v. 1, $338 \mathrm{p}$.

GARCIA, A., PETERS, J.A., PIEROBOM, C.R. et al. Principais problemas da cultura da batata-doce e algumas recomendações de pesquisa. HortiSul, Pelotas, v. 1, p. 30-33, 1989.

HAMMET, H.L., HERNANDEZ, T.P., MILLER, J.C. Inheritance of fiber content in the sweet potato, Ipomoea batatas. In: AMERICAN SOCIETY FOR HORTICULTURAL SCIENCE, 1966. Geneva. Proceedings... Beltsvillev: U.S. Plant Industry Station, 1966. v. 88 , p. $486-490$.

HERNANDEZ, T.P., TRAVIS, P.H., CONSTANTIN, R.J. $\boldsymbol{e}$ t al. Inheritance of and method of rating flesh colour in Ipomoea batatas. AMERICAN SOCIETY FOR HORTICULTURAL SCIENCE, 1965, Geneva. Proceedings... Beltsvillev: U.S. Plant Industry Station, 1965. v. 87, p. 387-390.

IBGE. Anuário Estatístico do Brasil, Rio de Janeiro: IBGE, 1995. 34p.

KARP, A., EDWARDS, K.J. Molecular techniques in the analysis of the extent and distribution of genetic diversity. In: AYAD, W.G., HODGKIN, T., JARADAT, T.A. et al. Molecular genetic techniques for plant genetic resources. Rome: IPGRI, 1997, p. 11-22.

ROHLF, F.J. NTSYS-pc numerical taxonomy and multivariate analysis system. Versão 1.5. New York: Exater, 1989, 191 p.

SCANDALIOS, J.G. Genetic control of molecular forms of enzymes in plants: a review. Biochemical genetics, New York, v. 3, p. 37-79, 1969.

VALLS, J.F.M. Caracterização morfológica, reprodutiva e bioquímica de germoplasma vegetal. In: ENCONTRO SOBRE RECURSOS GENÉTICOS, 1., 1988, Jaboticabal. Anais... Jaboticabal: FCAV, 1988. 208 p. p. 106-124.

Ciência Rural, v. 30, n. 1, 2000. 